\title{
PENGARUH PENGGUNAAN MEDIA VIRTUAL REALITY DENGAN MODEL PEMBELAJARAN KLASIKAL TERHADAP HASIL BELAJAR SISWA DI TK NEGERI PEMBINA SINGARAJA
}

\author{
Kadek Yuda Dharma1), Nyoman sugihartini'2), I Ketut Resika Arthana3) \\ 1,2,3 Fakultas Teknik dan Kejuruan, Universitas Pendidikan Ganesha \\ email: yudabully@yahoo.co.id, sugihartini@undiksha.ac.id, resika@undiksha.ac.id
}

\begin{abstract}
Abstrak
Abstrak-Tujuan penelitian ini adalah: (1) Untuk mengetahui perbedaan hasil belajar anak yang belajar menggunakan media Virtual Reality dengan anak yang belajar menggunakan media LKA pada tema pengenalan kendaraan di TK Negeri Pembina Singaraja (2) mengetahui respon anak setelah menggunakan media Virtual Reality pengenalan kendaraan. Jenis penelitian ini adalah eksperimen semu dengan desain Post Test Only Control Group Design. Populasi penelitian mencangkup seluruh anak kelompok B di TK Negeri Pembina Singaraja dengan jumlah 46 orang. Metode pengumpulan data yang digunakan lembar posttest untuk mengukur hasil belajar, dan metode angket untuk mengukur respon anak. Data hasil belajar kemudian dianalisis dengan melakukan uji prasyarat yang meliputi uji normalitas dan uji homogenitas. Hasil penelitian menunjukan (1) bahwa kelas eksperimen mempunyai hasil belajar lebih tinggi dibandingkan dengan kelas kontrol. Maka dapat dikatakan terdapat pengaruh penggunaan media virtual reality terhadap hasil belajar siswa di TK Negeri Pembina Singaraja. Hasil uji-t memperoleh thitung sebesar 4,794 dan tabel sebesar 1,699 untuk dk sebesar 29 dengan taraf signifikan 5\%. Berdasarkan kriteria pengujian diperoleh thitung $>$ tabel, ini berarti $\mathrm{H}_{0}$ ditolak. (2) respon siswa dari penerapan media virtual reality pada materi pengenalan kendaraan adalah sangat positif dilihat dari rata -rata skor hasil angket respon siswa yaitu 4,38.
\end{abstract}

Kata kunci: Quasi Eksperiment, Virtual Reality, Pengenalan Kendaraan

\begin{abstract}
Abstract - This research was aimed to: (1) investigate the difference of learning achievement between students who were taught by using Virtual Reality Media and students who are taught by using students' worksheet on public transportation theme in TK Negeri Pembina Singaraja, (2) know students' response after using Virtual Reality Media on introduction of Public Transportation. This research was quasi experiment of post - test only control group design. The population of this research were students of $B$ group in TK Negeri Pembina Singaraja which consist of 46 students in each group. Data collection methods used posttest sheet to measure learning outcomes, and questionnaire methods to measure the response of children. Learning result data is then analyzed by conducting prerequisite test wich includes normality test and homogeneity test. The results of this research show (1) that the experimental class had higher learning outcomes than the control class. So it can be said there is influence of the use of virtual reality media to student learning outcomes in TK Negeri Pembina Singaraja. Results of $t$-test get $t_{\text {count }}$ for to 4,794 and $t_{\text {table }}$ of to 1,699 for $d k$ of 29 with significant values of $5 \%$. Based on criteria obtained $t_{\text {count }}>t_{\text {table, }}$, this means that $H_{0}$ is rejected. (2) result analysis of students responses showed a very positive responses with an average responses value of 4,38 .
\end{abstract}

Keywords : Quasi Eksperiment, Virtual Reality, Introduction of Public Transportation 


\section{PENDAHULUAN}

Pendidikan anak usia dini (PAUD) adalah pendidikan yang ditujukan kepada anak dari usia 0 sampai 6 tahun yang dilakukan melalui pemberian rangsangan pendidikan untuk membantu pertumbuhan dan perkembangan jasmani dan rohani agar anak memiliki kesiapan dan pendidikan lebih lanjut. Kegiatan pembelajaran di TK (Taman Kanak-kanak) pada umumnya dikemas agar anak tertarik, sehingga anak dapat mengembangkan potensi yang dimiliki. Salah satu upaya yang dilakukan guru untuk membuat anak tertarik belajar adalah dengan menggunakan media pembelajaran yang menarik.

Menurut (Triyanto, Anitah, \& Suryani, 2013) media pembelajaran adalah sarana fisik untuk menyampaikan isi atau materi pembelajaran seperti buku, film, video dan sebagainya. Sehubungan dengan penggunaan media dalam kegiatan pembelajaran, para guru perlu cermat dalam pemilihan media yang ingin digunakan pada saat mengajar. Kecermatan dalam pemilihan media akan menunjang kegiatan pembelajaran yang dilakukannya. Disamping itu juga kegiatan pembelajaran menjadi menarik sehingga dapat menumbuhkan hasil belajar, dan perhatian anak menjadi terpusat kepada topik yang dibahas dalam kegiatan pembelajaran yang dilakukannya. Sehingga dengan demikian penggunaan media dalam pengajaran di kelas merupakan sebuah kebutuhan yang tidak dapat diabaikan.

Seiring dengan majunya perkembangan teknologi saat ini, teknologi juga dapat dimanfatkan sebagai salah satu alternatif dalam pemilihan media pembelajaran, salah satunya teknologi yang sedang berkembang saat ini yaitu VR atau Virtual Reality. Menurut (Parameswari, 2008) Virtual Reality merupakan suatu lingkungan yang disimulasikan oleh komputer. Media Virtual Reality dapat diterapkan diberbagai bidang salah satunya dibidang pendidikan yang bisa dijadikan media pembelajaran untuk mendukung proses pembelajaran. Menariknya media Virtual Reality ini untuk diterapkan pada penelitian ini yaitu untuk memberikan pengalaman belajar baru bagi anak dan memberikan sesuatu kegiatan yang menarik yang dimana anak akan dilibatkan langsung untuk melihat suatu dunia semu yang sebenarnya adalah gambar-gambar yang bersifat dinamis sehingga anak-anak merasa seolah-olah berada didunia nyata.

Selain menggunakan media pembelajaran yang dapat diaplikasikan dalam proses pembelajaran hendaknya juga menggunakan model pembelajaran untuk mempermudah proses penggunaan media pembelajaran. Model pembelajaran yang digunakan dalam penelitian ini yaitu model pembelajaran klasikal. (Lina, 2017) mengungkapkan bahwa model pembelajaran klasikal adalah pola pembelajaran yang dilakukan pendidik (guru) bersama sekelompok peserta didik dalam kelas secara bersamaan dengan aktivitas dan waktu yang sama pula.

Berdasarkan hasil observasi awal yang dilakukan dengan menggunakan teknik wawancara dan angket terhadap salah satu wali guru kelompok B di TK Negeri Pembina Singaraja pada tanggal 29 Januari 2018 dengan Ibu Ni Made Rediarpi, S.Pd., AUD. diperoleh data bahwa sumber belajar ataupun bahan ajar yang dipakai untuk kegiatan belajar mengajar khususnya pada tema pengenalan kendaraan yaitu guru masih menggunakan LKA (Lembar Kerja Anak) pada saat menerangkan materi, dan dari hasil pengamatan peneliti pada saat guru menjelasakan materi menggunakan media LKA (Lembar Kerja Anak) terlihat ada beberapa anak sedang berbicara dan tidak memperhatikan guru saat sedang mengajar. Menurut (Alfiana, 2017) penggunaan media LKA (Lembar Kerja Anak) kurang sesuai dengan penerapan kurikulum 2013 karena kurang menstimulasi kreativitas anak-anak. Dilihat dari hasil belajar anak di TK Negeri Pembina Singaraja yang berkategori berkembang. Hal tersebut dapat dilihat dari hasil nilai sebelumnya pada tema pengenalan kendaraan yang dapat dilihat pada Tabel 1. berikut. 
Tabel 1. Nilai Rata-Rata Pada Tema Kendaraan

\begin{tabular}{ccccc}
\hline No & Nilai & Kategori & Banyaknya Siswa & Persentase \\
\hline 1 & $1-5$ & Belum berkembang & - & - \\
2 & $6-10$ & Masih berkembang & 45 & 97,8 \\
3 & $11-15$ & Berkembang sesuai harapan & 1 & 2,2 \\
4 & $16-20$ & Berkembang sangat baik & - & - \\
\hline
\end{tabular}

Melihat dari permasalahan dilapangan yang menunjukan bahwa hasil belajar anak berkategori masih berkembang, maka dari itu peneliti bermaksud menggunakan media pembelajaran berbasis Virtual Reality untuk proses pembelajaran yang dimana tujuannya untuk memberikan pengalaman baru bagi anak dan memberikan sesuatu kegiatan yang menarik. Sehingga dengan adanya media pembelajaran Virtual Reality ini diharapkan mampu menumbuhkan minat belajar anak menjadi meningkat sehingga otomatis membuat hasil belajarnya juga akan meningkat.

Ada beberapa contoh penelitian sebelumnya terkait dengan pengaruh penggunaan media pembelajaran terhadap hasil belajar salah satunya yaitu dilakukan oleh (Rochman, 2017) yang berjudul "Pengaruh penggunaan media virtual reality terhadap hasil belajar materi tata surya siswa tunarungu kelas VIII SLB BC Kepanjen" hasil dari penelitian ini dapat dikatakan bahwa dengan penggunaaan media virtual reality berpengaruh terhadap peningkatan hasil belajar pada materi tata surya. Selanjutnya penelitian sebelumnya yang dilakukan oleh (Sari, 2011) yang berjudul "Pengaruh penggunaan media pembelajaran audio-visual bahasa inggris terhadap prestasi belajar Bahasa inggris siswa TK Islam Bani Hasim Singosari Malang" hasi penelitian ini dapat dikatakan bahwa penggunaan media audio visual berpengaruh signifikan meningkatkan prestasi belajar.

Berdasarkan permasalahan di atas peneliti memanfaatkan sebuah media pembelajaran virtual reality yang telah dibuat sebelumnya oleh Sutanaya. Dimana media pembelajaran ini sudah diuji ahli sebelumnya, namun media virtual reality ini belum dilakukan sebuah penelitian untuk mengukur hasil belajar.

Melihat identifikasi dilapangan yang menunjukan bahwa rata - rata hasil belajar anak yang masih berkategori berkembang pada tema kendaraan serta media virtual reality ini sebelumnya belum pernah dievaluasi terkait pengaruh dari media ini, maka dari itu penelitian ini sangat penting untuk dilaksanakan yang nantinya bukan hanya digunakan sebagai media pembelajaran saja, namun juga untuk meningkatkan hasil belajar anak di TK Negeri Pembina Singaraja.

Adapun langkah - langkah yang digunakan nanti dalam penelitian ini yaitu, (1) melakukan observasi dan orientasi awal ke sekolah yang akan dijadikan tempat untuk penelitian dan menentukan sampel penelitian, (2) menyusun instrument dan perangkat pembelajaran, (3) menerapkan media VR (Virtual Reality), (4) mengadakan tes akhir (posttest) kemudian menganalisa data hasil penelitian, (5) melakukan uji hipotesis dan menarik kesimpulan berdasarkan hasil uji hipotesis.

\section{METODE}

Penelitian ini menggunakan penelitian quasi experiment dengan desain penelitian post-test only control group design. Desain penelitian ini dipilih karena peneliti hanya ingin mengukur hasil belajar anak sesudah diberikan perlakuan. Desain penelitian post-test only control group design dapat dilihat pada Gambar 1.

\begin{tabular}{|ccc|}
\hline $\begin{array}{c}\text { Kelompok Eksperimen } \\
\text { Kelompok Kontrol }\end{array}$ & $\mathrm{X}$ & $\mathrm{O}_{1}$ \\
\hline Gambar 1. Desain penelitian post-test only \\
control
\end{tabular}


Keterangan:

$\mathrm{O}_{1} \quad$ : post-test kelompok eksperimen

$\mathrm{O}_{2} \quad$ : post-test kelompok kontrol

$\mathrm{X} \quad$ : treatment media VR

: treatment tanpa media VR

Penelitian ini dilaksanakan di TK Negeri Pembina Singaraja. Subyek yang diteliti yaitu anak kelompok B dengan populasi seluruh anak kelompok $B$ yang berjumlah 46 anak yang terdiri dari tiga kelompok B. Populasi penelitian dapat dilihat pada Tabel 2.

Tabel 2. Populasi Penelitian

\begin{tabular}{|c|c|c|c|}
\hline No & Nama Sekolah & $\begin{array}{c}\text { Jumlah } \\
\text { Kelas }\end{array}$ & $\begin{array}{c}\text { Jumlah } \\
\text { Anak }\end{array}$ \\
\hline \multirow{3}{*}{1} & \multirow{3}{*}{$\begin{array}{l}\text { TK Negeri } \\
\text { Pembina } \\
\text { Singaraja }\end{array}$} & B1 & 15 \\
\hline & & B2 & 16 \\
\hline & & B3 & 15 \\
\hline
\end{tabular}

Teknik pengambilan sampel dalam penelitian ini yaitu menggunakan simple random sampling. Cara yang digunakan untuk menentukan sampel adalah masing - masing kelas diberi nomor urut, selanjutnya dipilih 2 kelas secara random. Dari hasil pengundian tersebut didapatkan bahwa kelompok B2 sebagai kelas eksperimen dan kelompok B3 adalah kelas kontrol.

Tabel 3. Distribusi Sampel

\begin{tabular}{|l|c|c|}
\hline Kelompok & $\begin{array}{c}\text { Nama } \\
\text { Kelompok }\end{array}$ & $\begin{array}{c}\text { Jumlah } \\
\text { Siswa }\end{array}$ \\
\hline Kontrol & B2 & 16 \\
\hline Eksperimen & B3 & 15 \\
\hline \multicolumn{2}{|c|}{ Jumlah } & 31 \\
\hline
\end{tabular}

Prosedur eksperimen yang dilakasanakan pada penelitian ini adalah sebagai berikut:

- Melakukan observasi dan orientasi awal, yaitu menentukan sekolah yang dijadikan tempat penelitian dan melakukan pengamatann terkait permasalahn yang terjadi.

- Menentukan populasi serta sampel penelitian.

- Mengkonsultasikan perangkat pembelajaran dan instrument yang digunakan, dengan dosen pembimbing dan guru TK
- Melakukan uji judges terhadap intrumen yang digunakan dalam penelitian

- Melakukan revisi instrument

- Melaksanakan penelitian dengan menerapkan media VR pada kelas eksperimen dan tanpa media VR di kelas kontrol

- Mengadakan tes akhir pada kelas eksperimen dan kontrol. Untuk mengetahui hasil belajar anak.

- Menganalisis data hasil penelitian

- Menyusun laporan.

Teknik pengumpulan data yang digunakan adalah metode tes dan angket. Berdasarkan data yang sudah didapat dilakukan analisis deskriptif untuk mengetahui tinggi rendahnya kualitas dari hasil belajar. Metode analisis deskriptif adalah suatu cara yang dilakukan dengan cara menyusun secara sistematis dalam bentuk angka - angka atau persentase, mengenai suatu objek yang diteliti sehinggga diperoleh kesimpulan umum. Penentuan kualitas variabel-variabel tersebut, skor rata-rata (mean) tiap - tiap variabel dikonversikan dengan menggunakan kriteria rata - rata ideal dan standar deviasi (SD) seperti terlihat pada Tabel 4.

Tabel 4. Mean Ideal dan Standar Deviasi

\begin{tabular}{|l|c|}
\hline \multicolumn{1}{|c|}{ Rentangan Skor } & Kategori \\
\hline $\mathrm{MI}+1,5 \mathrm{SDI} \leq \bar{X}$ & Sangat Tinggi \\
\hline $\begin{array}{l}\mathrm{Ml}+0,5 \mathrm{SDI} \leq \bar{X}<\mathrm{Ml} \\
+1,5 \mathrm{SDI}\end{array}$ & Tinggi \\
\hline $\begin{array}{l}\mathrm{Ml}-0,5 \mathrm{SDI} \leq \bar{X}<\mathrm{MI}+ \\
0,5 \mathrm{SDI}\end{array}$ & Sedang \\
\hline $\begin{array}{l}\mathrm{Ml}-1,5 \mathrm{SDI} \leq \bar{X}<\mathrm{MI}- \\
0,5 \mathrm{SDI}\end{array}$ & Rendah \\
\hline $\bar{X}<\mathrm{Ml}-1,5 \mathrm{SDI}$ & Sangat Rendah \\
\hline
\end{tabular}

Keterangan:

X : Kualifikasi nilai

$\mathrm{Mi} \quad: \frac{1}{2}$ (skor tertinggi ideal + sko terendah ideal)

Sdi $\quad: \frac{1}{6}$ (skor tertinggi ideal - skor terendah ideal) 
Data hasil penelitian dianalisis dengan uji-t. asumsi yang harus dipenuhi dalam uji-t meliputi (1) uji normalitas dan (2) uji homogenitas. Pengujian asumsi dilakukan untuk mengetahui apakah data yang tersedia dapat dianalisis dengan statistik parametik atau tidak. Terkait dengan statistik yang digunakan untuk analisis data dalam penelitian ini:

\section{Uji Normalitas}

Pengujian normalitas dilakukan untuk meyakinkan bahwa sampel benar benar berasal dari populasi yang berdistribusi normal. Uji normalitas dilakukan untuk menentukan langkah pengujian dengan menggunakan pengujian statistic parametrik atau non parametrik. Hipotesis yang akan diujikan adalah:

$\mathrm{H}_{0} \quad$ :Tidak terdapat frekuensi sebaran data (normal).

$\mathrm{H}_{1} \quad$ :Terdapat perbedaan frekuensi sebaran data (tidak normal).

Uji normalitas data dilakukan dengan uji Chi-Square $\left(\mathrm{X}^{2}\right)$ dengan rumus:

$$
X^{2}=\sum \frac{\left(F_{0}-F_{h}\right)^{2}}{F_{h}}
$$

Keterangan:

$\mathrm{X}^{2} \quad$ : Chi-Square

$\mathrm{F}_{0} \quad$ : frekuensi yang diperoleh sampel

$F_{h} \quad$ : frekuensi yang diharapkan.

Kriteria pengujian dapat berdistribusi normal jika $X$ hitung $<X$ tabel, dengan taraf signifikan $5 \%$ dan derajat kebebasan $\mathrm{dk}=(\mathrm{k}-1)$.

\section{Uji Homogenitas}

Uji homogenitas ini dilakukan untuk mencari tingkat kehomogenan secara dua pihak yang diambil dari kelompok kelompok terpisah dari satu populasi yaitu kelompok kontrol dan kelompok eksperimen. Untuk menguji homogenitas varians untuk kedua kelompok digunakan uji F. Hipotesis yang akan diujikan adalah:
$\mathrm{H}_{0}$ : Tidak terdapat perbedaan varians antara kelompok eksperimen dan kelompok kontrol

$\mathrm{H}_{1} \quad$ : Terdapat perbedaan varians antara kelompok eksperimen dan kelompok kontrol.

Uji homogenitas dilakukan dengan uji $\mathrm{F}$ dengan rumus:

$$
F_{\text {hit }}=\frac{s_{1}^{2}}{s_{2}^{2}}
$$

Keterangan :

$\mathrm{s}_{1}{ }^{2} \quad$ : varians terbesar

$\mathrm{S}_{2}{ }^{2} \quad$ : varians terkecil

Kriteria pengujian, , jika Fhit $F_{\text {hit }} \geq$ $F_{\alpha(n 1-1, n 2-1)}$ maka sampel tidak homogen dapat melakukan pengujian dengan menggunakan rumus polled varians dan jika $F_{\text {hit }} \geq F_{\alpha(n 1-1, n 2-1)}$ maka sampel homogen dapat melakukan pengujian dengan dengan menggunakan rumus separated varians. Pengujian dilakukan pada taraf signifikan $5 \%$ dengan derajat kebebasan untuk pembilang $n_{1}-1$ dan derajat kebebasan untuk penyebut $n_{2}-1$.

Pedoman untuk menetapkan homogenitas yaitu sebagai berikut.

- Menetapkan taraf signifikansi, dalam hal ini, yaitu $\alpha=0,05$.

- Jika signifikansi yang diperoleh $>\alpha$, maka variansi setiap sampel homogen.

- Jika signifikansi yang diperoleh < $\alpha$, maka variansi setiap sampel tidak homogen.

\section{Uji Hipotesis}

Untuk menguji hipotesis dalam penelitian ini, yaitu menggunakan uji-t sampel berkorelasi, dengan rumus:

$$
t=\frac{\overline{x 1}-\overline{x 2}}{\sqrt{\frac{s 1^{2}}{n 1}+\frac{s 2^{2}}{n 2}-2 r\left(\frac{s 1}{\sqrt{n 1}}\right)\left(\frac{s 2}{\sqrt{n 2}}\right)}}
$$


Keterangan:

$$
\begin{array}{ll}
\overline{x 1} & =\text { Rerata sampel satu } \\
\overline{x 2} & =\text { Rerata sampel dua } \\
\mathrm{S}_{1} & =\text { Simpangan baku satu sampel } \\
\mathrm{S}_{2} & =\text { Simpangan baku sampel dua } \\
\mathrm{S}_{1}{ }^{2} & =\text { Varian sampel satu } \\
\mathrm{S}_{2}{ }^{2} & =\text { Varian sampel dua } \\
\mathrm{r} & =\text { korelasi Antara dua sampel }
\end{array}
$$

\section{Respon Siswa}

Respon siswa terhadap penggunaan media Virtual Reality pengenalan kendaraan dikumpulkan dengan menggunakan angket. Untuk mencari ratarata atau mean $(\bar{X})$ dapat dilakukan dengan membagi jumlah semua skor $\left(\sum X\right)$ dengan jumlah siswa $(\mathrm{N})$ dengan rumus sebagai berikut:

$$
\bar{X}=\frac{\sum X}{N}
$$

\section{Keterangan :}

$\bar{X} \quad=$ Skor rata - rata respon siswa

$X \quad=$ jumlah total skor respon siswa

Untuk mencari mean ideal (MI) dan standar deviasi ideal (SDI) dapat dilakukan dengan rumus sebagai berikut.

$\mathrm{Mi}=\frac{1}{2}$ (skor maksimal ideal + skor terendah ideal)

Sdi $=\frac{1}{6}$ (skor tertinggi ideal - skor terendah ideal)

Untuk kriteria pemberian skor respon siswa dapat dilihat dalam Tabel 5.

Tabel 5. Kriteria Pemberian Skor Respon

\begin{tabular}{|l|c|c|}
\multicolumn{3}{|c}{ Siswa } \\
\hline Pernyataan & S & TS \\
\hline Positif & 1 & 0 \\
\hline Negatif & 0 & 1 \\
\hline
\end{tabular}

Respon siswa terhadap penggunaan media virtual reality yang diterapkan dapat diketahui berdasarkan Tabel 6 .

Tabel 6.Kriteria Respon Siswa

\begin{tabular}{|l|l|}
\hline \multicolumn{1}{|c|}{ Rentangan Skor } & \multicolumn{1}{c|}{ Kategori } \\
\hline $\mathrm{MI}+1,5 \mathrm{SDI} \leq \bar{X}$ & Sangat Positif \\
\hline $\mathrm{MI}+0,5 \mathrm{SDI}$ & Positif \\
$\leq \bar{X}<\mathrm{MI}+1,5 \mathrm{SDI}$ & \\
\hline $\mathrm{MI}-0,5 \mathrm{SDI}$ & Cukup Positif \\
$\leq \bar{X}<\mathrm{MI}+0,5 \mathrm{SDI}$ & \\
\hline $\mathrm{MI}-1,5 \mathrm{SDI}$ & Kurang \\
$\leq \bar{X}<\mathrm{MI}-0,5 \mathrm{SDI}$ & \\
\hline $\bar{X}<\mathrm{MI}-1,5 \mathrm{SDI}$ & Sangat Kurang \\
\hline
\end{tabular}

\section{HASIL DAN PEMBAHASAN}

Hasil penelitian ini meliputi analisis deskriptif dan analisis statistik yang mengungkap pengaruh variabel bebas terhadap variabel terikat. Variabel bebas dalam penelitian ini adalah media pembelajaran virtual reality pada materi pengenalan kendaraan sedangkan variabel terikat dalam penelitian ini adalah hasil belajar anak terhadap materi pengenalan kendaraan.

Sebelum menentukan sampel, terlebih dahulu menentukan anggota populasi. Populasi yang digunakan pada penelitian ini adalah seluruh anak kelompok B. Total anak sebanyak 46 anak. Teknik pengambilan sampel dalam penelitian ini yaitu dengan cara simple random sampling. Hasil pengundian didapatkan bahwa kelompok B2 sebagai kelas eksperimen dan B3 adalah kelas Kontrol. Kelas eksperimen adalah kelompok yang diberi perlakuan yaitu dengan pembelajaran yang menggunakan media virtual reality, Kelas kontrol adalah kelompok siswa yang belajar dengan LKA (Lembar Kerja Anak). Penelitian ini dilaksanakan dalam 4 kali pertemuan, yang terdiri dari 3 kali proses pembelajaran dan 1 kali pertemuan untuk posttest yang dilakukan pada kelas eksperimen dan kontrol. Tahapan untuk mendapatkan data yaitu kelas ekperimen diberikan perlakuan dengan belajar menggunakan media virtual reality selama 3 kali pertemuan proses pembelajaran, dan kelas kontrol menggunakan Lembar kerja anak (LKA). 
Setelah diberikan perlakuan, selanjutnya diberikan tes akhir pada waktu yang bersamaan di kelas eksperimen dan kelas kontrol pada hari kamis, tanggal 17 Mei 2018 dengan tujuan untuk mengetahui hasil belajar siswa setelah diberi perlakuan.

Hasil belajar anak kelompok B di TK Negeri Pembina Singaraja pada tema pengenalan kendaraan dengan media virtual reality didapat bahwa rata - rata hasil belajar yang dicapai anak kelompok eksperimen adalah 25,9 sedangkan ratarata post-test pada hasil belajar kelompok kontrol sebesar 22,03. Dengan demikian, rata-rata posttest hasil belajar pada kelompok eksperimen lebih besar dibandingkan kelompok kontrol.

Sebelum dilakukan pengujian hipotesis. Uji prasyarat analisis terlebih dahulu meliputi dua hal, yaitu (1) uji normalitas data dan (2) uji homogenitas varians antar kelompok. Perhitungan normalitas dan homogenitas dngan uji-t menggunakan Microsoft Excel 2010 dengan SPSS 16.0 hasilnya tidak jauh berbeda, di mana kedua kelompok baik kelompok eksperimen maupun kelompok kontrol memiliki data yang normal yaitu tidak terdapat perbedaan frekuensi sebaran data kelompok eksperimen dan kelompok Kontrol. Kedua kelompok juga memiliki data yang homogen yaitu tidak terdapat perbedaan varians antara kelompok eksperimen dan kelompok kontrol.

Perhitungan uji hipotesis dengan uji-t menggunakan Microsoft Excel 2010, dengan taraf signifikan $5 \%$ dan derajat kebebasan 29 diperoleh $t_{\text {hitung }}=4,794$ dan $t_{\text {tabel }}=1,699$ Karena thitung $>t_{\text {tabel }}$ maka $\mathrm{H}_{0}$ ditolak dan $\mathrm{H}_{1}$ diterima. Sedangkan analisis uji-t dengan SPSS 16.0 mendapatkan hasil $t_{\text {hitung }}=4,911$ dan $t_{\text {tabel }}$ dicari dengan tabel distribusi t pada taraf signifikan $5 \%$ satu sisi dan derajat kebebasan (df) adalah 29, sehingga tabel $=$ 1,699 karena $t_{\text {hitung }}>t_{\text {tabel }}$, maka $\mathrm{H}_{0}$ ditolak. Hal ini menunjukan bahwa bahwa terdapat hasil belajar yang lebih tinggi antara siswa yang belajar menggunakan media virtual reality dan siswa yang belajar menggunakan lembar kerja anak pada kelompok B di TK Negeri Pembina
Singaraja. Hal ini menunjukan bahwa kelas yang dibelajarkan dengan menggunakan media virtual reality memiliki nilai rata-rata lebih tinggi apabila dibandingkan dengan kelas yang dibelajarkan menggunakan lembar kerja anak (LKA). Hal ini disebabkan karena dampak positif dari pembelajaran menggunakan media virtual reality.

Selama pelaksanaan pembelajaran dengan menggunakan media virtual reality, kegiatan yang dilakukan anak yaitu mengamati dan mendengarkan. Melalui media virtual reality anak mendapatkan pengalaman langsung tanpa harus pergi ke objek yang diamati. Contohnya, ketika anak diajak untuk mengetahui kendaraan yang ada di udara, anak tidak harus berkunjung ke bandara untuk dapat melihat kendaraan tersebut. Karena anak sudah dapat mengamati kendaraan di udara melalui media virtual reality. Hal ini juga didukung oleh teori yang disampaikan oleh (Randi, 2017) yang menyatakan bahwa media virtual reality mudah digunakan, memberikan informasi visual yang lebih baik, menyenangkan sehingga siswa tidak merasa bosan serta membantu meningkatkan pemahaman siswa,

Sedangkan ketika menggunakan LKA (Lembar Kerja Anak) kegiatan yang dilakukan anak yaitu mengamati dan menggambar objek yang sudah di sediakan oleh guru. Dimana melalui media LKA anak hanya bisa melihat kendaraan berupa gambar. Menurut (Pratiwi, 2017), Pada hakikatnya daya ingat sangat berhubungan langsung dengan pengalaman yang telah dilihat dan yang terjadi di sekeliling anak. Oleh karena itu penggunaan media virtual reality membuat ingatan anak lebih kuat sehingga hasil belajar juga meningkat, dibandingkan penggunaan LKA yang hanya memberikan petunjuk dan langkah pengerjaan tugas tanpa memberikan pengalaman terhadap anak.

Respon anak terhadap penggunaan media virtual reality berada pada kategori sangat positif. Hal tersebut dapat dilihat pada Gambar 2. Berikut. 


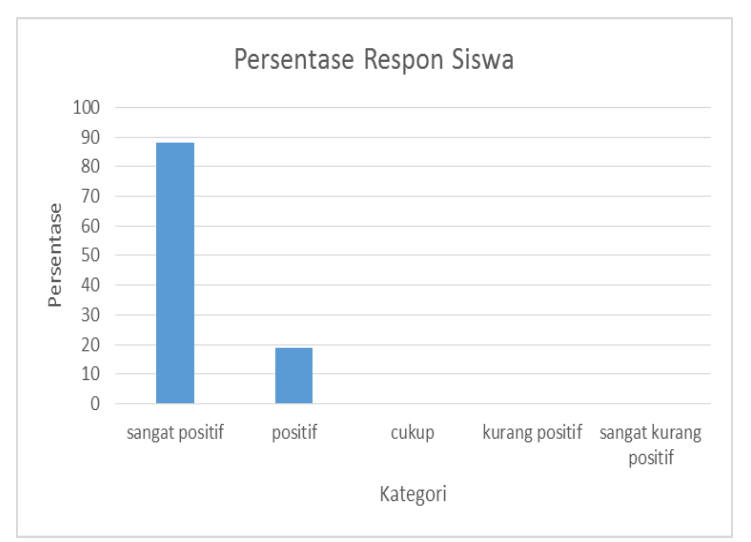

Gambar 2. Histogram respon siswa

Keadaan seperti ini dapat dijadikan modal untuk menciptakan suasana belajar yang efektif agar bisa meningkatkan hasil belajar anak yang lebih tinggi. Respon positif anak akan menjadi langkah awal untuk menuju kepada lingkungan belajar yang efektif. Jadi, dengan diperoleh respon anak yang sangat positif terhadap penerapan media virtual reality pada materi pengenalan kendaraan di dalam kelas dapat mengindikasikan bahwa media virtual reality dapat diterima dengan baik oleh anak. Oleh karena itu, penerapan media virtual reality pada materi pengenalan kendaraan ini dapat dijadikan sebagai langkah alternative dalam pembelajaran di kelas.

Berdasarkan pertimbangan pertimbangan teoritik dan operasional, maka Implikasi dari penelitian ini jika dilihat dari teori belajar konstruktivisme adalah proses belajar dan pembelajaran dikelas siswa harus terlibat aktif dan siswa menjadi pusat kegiatan belajar dan pembelajaran dikelas. Siswa harus dapat mengaplikasikan ide-ide mereka sendiri, siswa harus mengkonstruksikan pengetahuan dibenak mereka sendiri sehingga hasil belajar dicapai dengan lebih baik. Berdasarkan hal itu bahan atau media ajar yang dapat digunakan untuk mencapai hasil belajar dengan lebih baik adalah bahan atau media ajar virtual reality pada materi pengenalan kendaraan.

\section{SIMPULAN DAN SARAN}

Berdasarkan hasil penelitian dan pembahasan, maka penulis dapat menarik kesimpulan sebagai berikut:

- Terdapat hasil belajar yang lebih tinggi antara siswa yang belajar menggunakan media virtual reality dan siswa yang belajar menggunakan LKA (Lembar Kerja Anak) pada materi pengenalan kendaraan anak kelompok B TK Negeri Pembina Singaraja. Dilihat rata-rata hasil belajar kelompok eksperimen dengan penerapan media virtual reality adalah 25,9 sedangkan rata-rata posttest untuk kelompok kontrol sebesar 22,03 . Berdasarkan rata-rata hasil belajar tersebut maka dapat disimpulkan bahwa hasil belajar lebih tinggi terdapat pada anak yang yang menggunakan media virtual reality.

- Hasil dari analisis respon siswa dari penerapan media virtual reality pada materi pengenalan kendaraan dilihat dari rata - rata skor respon siswa sebesar 4,38 adalah termasuk dalam kategori sangat positif.

Dari hasil penelitian yang diperoleh, maka peneliti memberikan saran-saran yaitu:

- Hasil penelitian ini menunjukkan bahwa anak yang belajar dengan menggunakan media virtual reality memperoleh hasil belajar yang lebih baik daripada anak yang menggunakan media pembelajaran konvensional. Oleh karena itu, penulis menyarankan kepada guru pengajar untuk menerapkan media pembelajaran media virtual reality pada proses pembelajaran selanjutnya.

- Peneliti menyarankan kepada peneliti lain yang akan melakukan penelitian sejenis agar bisa mengkondisikan keadaan kelas sebaik mungkin ketika melaksanakan tes akhir (posttest).

\section{DAFTAR PUSTAKA}

Alfiana, F. S. 2017. Pengembangan Media Pembelajaran Watube Untuk Mengenalkan Sifat-Sifat Air Pada 
Anak Kelompok B. Universitas Negeri Yogyakarta.

Arifin, Z. 2011. Penelitian Pendidikan: Metode dan Paradigma Baru. Bandung: Remaja Rosdakarya.

Departemen Pendidikan Nasional. 2003. Undang Undang No 20 Tahun 2003. Jakarta: Depdiknas.

Lina. 2017. Pelaksanaan Model Pembelajaraan Klasikal Di TK Kecamatan Danau Kerinci. Fakultas Keguruan Dan IImu Pendidikan.

Novita, P. R. 2017. Pengaruh Pemanfaatan Media Video Terhadap Hasil Belajar Siswa Pada Materi Koloid Di Kelas XI SMAN 10 Aceh Barat Daya. Fakultas Tarbiyah dan Keguruan Universitas Islam Negeri ARRaniry Darussalam, Banda Aceh.

Parameswari, C. (2008). Implementasi Lingkungan Virtual Reality Pada Aplikasi Bersepda Di UI Dengan Memanfaatkan Kacamata Wireless 3 Dimensi E-Dimensional Untuk PC. Fakultas Teknik Universitas Indonesia.

Sutanaya, I. G. 2017. Pengembangan Virtual Reality Pengenalan Kendaraan Untuk Anak Usia Dini. Jurnal Nasional Pendidikan Teknik Informatika (JANAPATI) Volume 6, Nomor 1, Maret 2017.

Setiarini, P. 2016. Pengaruh E-Modul Berbasis Metode Pembelajaran Problem Based Learning Terhadap Hasil dan Motivasi Belajar Siswa Pada Mata Pelajaran Pemograman Dasar (Studi Kasus: Kelas $\mathrm{X}$ Multimedia di SMK Negeri Singaraja). . Kumpulan Artikel Mahasiswa Pendidikan Teknik Informatika (KARMAPATI), ISSN 2252-9063.
Sugihartini, N., \& Agustini, K. (2017). Asesmen Otentik sebagai Pendukung Desain Instruksional Jaringan Komputer Berstrategi Blended-Learning dengan Pendekatan Konstruktivistik. Journal of Education Research and Evaluation. Vol. 1 (2) pp. 82-90.

Sugihartini, N., \& Jayanta, N. L. (2017). Emodul Strategi Pembelajaran Berbasis CAI dengan Project Based Learning (Kajian Respon Pengguna Sistem). Seminar Nasional Riset Inovatif.

Sugiyono. 2014. Metode Penelitian Pendidikan Pendekatan Kuantitatif, Kualitatif Dan R\&D. Bandung: Alfabeta.

Sutirman. 2013. Media \& Model - model Pembelajaran Inovatif. Yogyakarta: Graha IImu.

Triyanto, E., Anitah, S., \& Suryani, N. (2013). Peran Kepemimpinan Kepala Sekolah Dalam Pemanfaatan Media Pembelajaran Sebagai Upaya Peningkatan Kualitas Proses Pembelajaran. Jurnal Teknologi Pendidikan.

Wardani, F. 2016. Pengaruh Media Bahan Alam Terhadap Perkembangan Motorik Halus Anak Usia Dini Di Kelompok Bermain Ma'had Allami Kabupaten Jember Tahun ajaran 2014/2015. Fakultas Keguruan Dan IImu Pendidikan Universitas Jember.

Yusuf, A. 2014. Metodelogi Penelitian Kuantitatif, Kualitatif \& Penelitian Gabungan . Jakarta : Prenadamedia Group.

Pratiwi, A. F. (2017). Peningkatan Daya Ingat Anak Usia Dini Melalui Media Mind Mapping Pada Kelompok B Di TK Islam Al-Muttaqin Kota Jambi. Universitas Negeri Jambi. 
Randi, A. (2017). Pemanfaatan Teknologi Virtual Reality Sebagai Media Pembelajaran Interaktif Untuk Sistem Tata Surya Berbasis Android. Universitas Islam Negeri Alauddin Makasar. 